https://doi.org/10.22319/rmcp.v12i1.5267

Artículo

\title{
Detección de anticuerpos de Neospora spp. en caballos, asociados a diferentes
} factores de riesgo en México

\author{
Kenia Jasher Padilla-Díaz ${ }^{\text {a }}$ \\ Leticia Medina-Esparza ${ }^{a^{*}}$ \\ Carlos Cruz- Vázquez a \\ Irene Vitela-Mendoza ${ }^{\text {a }}$ \\ Juan F. Gómez-Leyva b \\ Teódulo Quezada-Tristán ${ }^{\mathrm{c}}$
}

${ }^{a}$ Instituto Tecnológico El Llano Aguascalientes, Km 18 Carretera Ags-SLP., Municipio de El Llano, Ags., 20330, Aguascalientes, México.

${ }^{\mathrm{b}}$ Universidad Autónoma de Aguascalientes. Centro de Ciencias Agropecuarias, Aguascalientes, México.

${ }^{\mathrm{C}}$ Instituto Tecnológico de Tlajomulco, Tlajomulco de Zúñiga, Jalisco, México.

* Autor de correspondencia: Imedinaesparza@ yahoo.com.mx

\section{Resumen:}

Neospora spp. es un parásito protozoario causante de abortos y enfermedad del Sistema Nervioso Central (SNC) en diversas especies domésticas y silvestres. En equinos, se le ha involucrado como causa de aborto, mortalidad neonatal y enfermedades del SNC. La especie identificada en equinos es distinta a Neospora caninum y se denomina Neospora hughesi. El objetivo del presente, fue detectar la presencia de anticuerpos anti-Neospora spp., asociados a factores de riesgo en caballos de México. Se realizó una encuesta de cada cuadra y animales individuales de 
cuatro regiones del país (Centro, Norte, Occidente y Sur) para identificación de los factores de riesgo. Se obtuvo un total de 684 muestras de sueros de caballos de las diferentes regiones, $52.3 \%$ (358) machos y $47.7 \%$ (326) hembras. Los sueros fueron conservados a $-20{ }^{\circ} \mathrm{C}$. El diagnóstico se realizó mediante la técnica de inmunofluorescencia indirecta (IFI), los resultados de este fueron analizados para estimar la asociación entre la seropositividad y los factores de riesgo. La seroprevalencia a Neospora spp. fue de $2.34 \%$ en la población estudiada; los casos positivos se encontraron principalmente en tres de las cuatro regiones incluidas, que presentaron una relación significativa a la presencia de anticuerpos anti-Neospora spp.; la convivencia de los caballos con otros animales obtuvo un valor de OR de 2.34 (IC 95\%: 0.28 - 19.0; $P<0.04$ ). Se concluye que, Neospora spp., está presente en los caballos de México.

Palabras clave: Neospora hughesi, Neospora spp., Equinos, Caballos, Factores de riesgo.

Recibido: 19/02/2019

Aceptado: 12/03/2020

\section{Introducción}

La neosporosis fue asociada por primera vez en caballos al reportarse la evidencia de Neospora caninum en un feto tardío y en la placenta ${ }^{(1)}$; el segundo caso, fue en un potro de un mes de edad, que presentó ceguera congénita y desórdenes neurológicos ${ }^{(2)}$. Estudios moleculares, antigénicos y estructurales demuestran que la especie aislada en caballos con problemas neurológicos es diferente a la reportada, y la denominan Neospora hughesi ${ }^{(3)}$. Las especies caninum y hughesi son protozoarios intracelulares obligados del género Neospora, pertenece al Phylum Apicomplexa, clase Sporozoea, orden Eucoccidiida, familia Sarcocystidae ${ }^{(4)}$. La N. caninum en caballos ha sido asociada a abortos y problemas reproductivos ${ }^{(5-8)}$, mientras que $N$. hughesi está relacionada con enfermedades neurológicas ${ }^{(9-11)}$, también, asociada con Sarcosystis neuronae, causante de mieloencefalitis protozoaria equina (MPE), identificada como una enfermedad neurológica grave de los caballos, que produce pérdidas significativas en la producción equina, principalmente reportado en Estados Unidos ${ }^{(12)}$.

Los hospederos definitivos de $N$. caninum identificados son el perro doméstico ${ }^{(13)}$, coyote $^{(14)}$, dingo australiano ${ }^{(15)}$ y lobo gris ${ }^{(16)}$, y como hospederos intermediarios varias especies silvestres y domésticas $^{(17)}$, sin embargo, los hospederos definitivos de $N$. hughesi, no se han identificado y el caballo es considerado como único hospedero intermediario potencial ${ }^{(18)}$. La infección puede 
ocurrir debido a la ingestión de ooquistes esporulados en alimento o agua contaminados; con respecto a la transmisión vertical actualmente es considerada solo como ruta alternativa ${ }^{(19,20)}$.

Las técnicas serológicas utilizadas para la identificación de anticuerpos de Neospora spp., son: técnica de inmunofluorescencia indirecta (IFI), ensayo inmunoenzimático (ELISA), test de aglutinación de Neospora (TAN), Western blot (WB), manejan taquizoítos de $N$. caninum como antígeno, el uso de éste supone seropositividad para Neospora spp., debido a la reacción cruzada que presenta el parásito $^{(21)}$, solo la biotecnología del ADN se utiliza para distinguir $N$. hughesi de $N$. caninum $^{(22)}$. El objetivo del estudio fue detectar la presencia de anticuerpos anti-Neospora spp., asociados a factores de riesgo en caballos de México.

\section{Material y métodos}

\section{Lugar de estudio}

Para este estudio se seleccionaron cuatro regiones de México según sus características geográficas y climáticas: Región Centro, Región Norte, Región Occidente, y Región Sur (Figura $1)$.

Figura 1: División geográfica de México por regiones de estudio

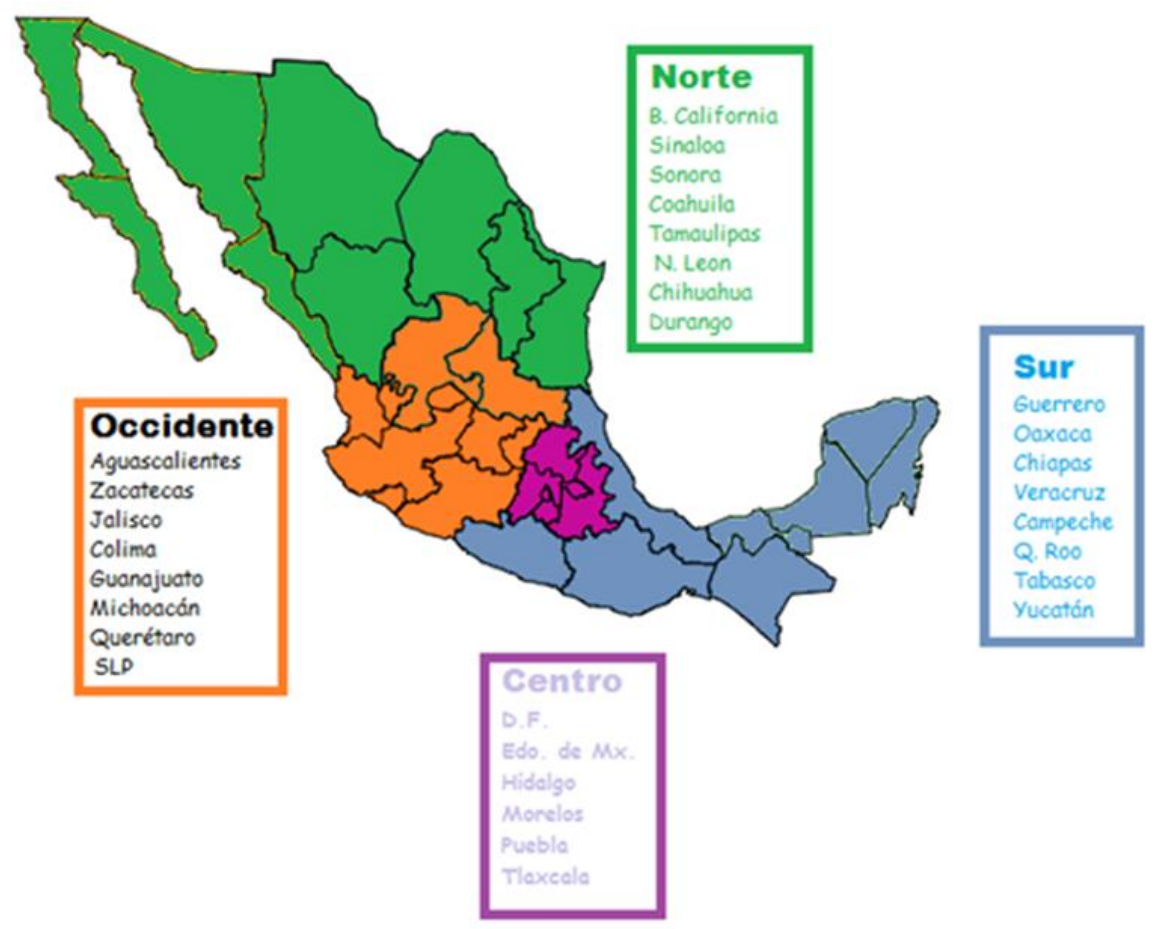




\section{Diseño del trabajo}

Se realizó un estudio epidemiológico de tipo transversal, durante el periodo comprendido del mes de octubre de 2016 a octubre de 2017. Se llevó a cabo en dos etapas; de campo y de laboratorio. Durante la etapa de campo se colectaron $5 \mathrm{ml}$ de sangre completa en tubos vacutainer sin anticoagulante (BD Vacutainer ${ }^{\circledR}$ ) por punción de la vena yugular de caballos aparentemente sanos, obteniendo un total de 684 muestras de las cuales correspondieron 75 a la Región Centro (10.96 \%), 54 a la Región Norte (7.89 \%), 298 a la Región Occidente (43.57\%) y 257 a la Región Sur (37.57\%).

A todos los animales que fueron muestreados se les realizó un examen físico para determinar su estado de salud, y se aplicó una encuesta a los propietarios de los caballos, la cual consistió en recabar información de las características generales de los animales (raza, edad, sexo y estado reproductivo) y sobre el manejo especifico de la cuadra (uso de caballos, alimentación, alojamiento, fuentes de agua y contacto con otros animales). Las muestras de sangre obtenidas, se transportaron al laboratorio en refrigeración a $4.0{ }^{\circ} \mathrm{C}$, donde fueron centrifugadas a 3,500 rpm durante 10 min para obtener el suero, el cual posteriormente fue separado con una pipeta de transferencia a tubos Eppendorf ${ }^{\mathrm{TM}}$ de $1.5 \mathrm{ml}$, los cuales se almacenaron a $-20^{\circ} \mathrm{C}$ hasta su análisis.

\section{Prueba serológica}

La técnica de IFI, se realizó mediante un kit comercial para detectar anticuerpos IgG circulantes específicos de Neospora spp., utilizando laminillas antigenadas con taquizoitos de $N$. caninum cepa NC-1, (SLD-IFA-NC) y conjugado anti-equine IgG marcado con isotiacianato de fluoresceína (FITC-Conjugate VMRD). Las muestras de suero se diluyeron 1:25 en solución salina tamponada con fosfato (PBS). Se usó un control positivo y negativo como estándar, realizando la técnica de acuerdo con las recomendaciones del fabricante. Todos los sueros que presentaron fluorescencia en la dilución inicial se consideraron positivos y se diluyeron aún más hasta el punto final del título. La dilución más alta del suero que presenta fluorescencia se consideró como el título de punto final en esta técnica.

\section{Análisis de los datos}

Los datos generados a través de la encuesta (variables independientes) y los resultados positivos a la presencia de anticuerpos de Neospora spp. (variable dependiente) fueron analizados por el Software Estadístico STATA versión 10. Se obtuvo la distribución de la seroprevalencia con las variables independientes. La asociación entre la seroprevalencia de $N$. caninum en caballos y la presencia de otros animales, se realizó mediante un modelo de regresión logística (Ji cuadrada), 
considerando $P<0.05$. Finalmente se calcularon las razones de probabilidad (OR) entre los resultados positivos, los resultados negativos y la relación con el intervalo de confianza.

\section{Resultados}

Se detectó la presencia de anticuerpos anti-Neospora spp. en muestras de suero de caballos analizados mediante la técnica de IFI (Nc-1 Neospora caninum); las muestras de suero que presentaron títulos en una dilución de 1:50 fueron consideradas positivas. La seroprevalencia general obtenida fue de $2.34 \%(16 / 684)$.

En base al total de animales seropositivos a Neospora spp, se analizó la variable estado reproductivo; donde el $50 \%$ (8/16) de los animales presentaron anticuerpos anti-Neospora spp, en diferentes niveles de dilución, mayores al punto de corte (1:50), en el Cuadro 1, se observa que, en los machos enteros (4/16), la dilución máxima fue de 1:200, sin embargo, las hembras gestantes (3/16) alcanzaron diluciones de 1:200 y dos de ellas 1:400.

Cuadro 1. Porcentaje de niveles de titulación de anticuerpos de Neospora spp. según diluciones seriadas mediante la técnica de IFI

\begin{tabular}{lllll}
\hline Animales & Títulos & & & \\
& $\mathbf{1 : 5 0}$ & $\mathbf{1 : 1 0 0}$ & $\mathbf{1 : 2 0 0}$ & $\mathbf{1 : 4 0 0}$ \\
\hline Castrado & $18.75(3 / 16)$ & - & - & - \\
Entero & $25.00(4 / 16)$ & $18.75(3 / 16)$ & $6.25(1 / 16)$ & - \\
Potranca & $6.25(1 / 16)$ & - & - & - \\
Yegua & $12.50(2 / 16)$ & - & - & - \\
Gestante & $18.75(3 / 16)$ & $18.75(3 / 16)$ & $18.75(3 / 16)$ & $12.50(2 / 16)$ \\
Vacía & $6.25(1 / 16)$ & - & - & - \\
Recién parida & $12.50(2 / 16)$ & $12.50(2 / 16)$ & - & - \\
Total & $100.0(16 / 16)$ & $50.00(8 / 16)$ & $25.00(4 / 16)$ & $12.50(2 / 16)$ \\
\hline
\end{tabular}

Las variables de la encuesta incluidas en el estudio, se analizaron para identificar los posibles factores de riesgo asociados a la presencia de anticuerpos anti-Neospora spp. Los resultados se presentan en el Cuadro 2, observándose que, el mayor número de casos positivos (62.50\%) fue en caballos de la región occidente, en la centro, de $6.25 \%$, sur $31.25 \%$ y en la región norte no hubo casos positivos, esta variable no tuvo significancia estadística $(P<0.05)$. Del total de animales positivos a la presencia de anticuerpos anti- Neospora spp. el $43.75 \%$ fueron machos y el $56.25 \%$ hembras. Para la variable convivencia de los caballos con otros animales se observó un OR de 2.34 (IC 95\%: 0.28 - 19.0; $P=0.04$ ). Mientras que las variables uso de los caballos y alojamiento mostraron valores de $P<0.20$, al ser analizadas con regresión logística la variable 
alojamiento obtuvo un OR de 3.12. Las variables edad, raza, estado reproductivo y fuente de agua no presentaron significancia estadística $(P>0.05)$.

Cuadro 2: Distribución de Neospora spp. en sueros positivos y negativos en caballos de México y los factores asociados

\begin{tabular}{|c|c|c|c|c|c|c|}
\hline \multirow{2}{*}{ Variable } & \multicolumn{2}{|c|}{ Muestras } & \multicolumn{2}{|c|}{ Neospora spp. } & \multirow{2}{*}{$P$-value } & \multirow{2}{*}{ OR (CI 95\%) } \\
\hline & $\mathbf{N}$ & $\%$ & + & - & & \\
\hline \multicolumn{7}{|l|}{ Región: } \\
\hline Centro & 75 & 10.96 & $1(6.25)$ & 74 & \multirow{4}{*}{0.36} & \multirow{4}{*}{$79(0.49-1.29)$} \\
\hline Norte & 54 & 7.89 & $0(0.00)$ & 54 & & \\
\hline Occidente & 298 & 43.57 & $10(62.50)$ & 288 & & \\
\hline Sur & 257 & 37.57 & $5(31.25)$ & 252 & & \\
\hline \multicolumn{7}{|l|}{ Sexo: } \\
\hline Macho & 358 & 52.34 & $7(43.75)$ & 351 & \multirow[t]{2}{*}{0.49} & \multirow[t]{2}{*}{$0.45(0.03-6.18)$} \\
\hline Hembra & 326 & 47.66 & $9(56.25)$ & 317 & & \\
\hline \multicolumn{7}{|l|}{ Edad: } \\
\hline Joven (7-24 m) & 68 & 9.94 & $1(6.25)$ & 67 & \multirow{3}{*}{0.21} & \multirow{3}{*}{$1.09(0.47-2.51)$} \\
\hline Adulto (25-48 m) & 375 & 54.82 & $10(62.50)$ & 365 & & \\
\hline Viejo $(>48 \mathrm{~m})$ & 241 & 35.23 & $5(31.25)$ & 236 & & \\
\hline \multicolumn{7}{|l|}{ Raza: } \\
\hline Criollo & 262 & 38.30 & $6(37.50)$ & 256 & \multirow[t]{2}{*}{0.68} & \multirow[t]{2}{*}{$1.09(0.22-5.40)$} \\
\hline Puro & 422 & 61.70 & $10(62.50)$ & 412 & & \\
\hline \multicolumn{7}{|l|}{ Estado reproductivo: } \\
\hline Entero & 293 & 42.84 & $4(25.00)$ & 62 & \multirow{7}{*}{0.13} & \multirow{7}{*}{$0.69(0.32-1.49)$} \\
\hline Castrado & 65 & 9.50 & $3(18.75)$ & & & \\
\hline Potranca & 26 & 3.80 & $1(6.25)$ & $\begin{array}{l}25 \\
110\end{array}$ & & \\
\hline Yegua & 121 & 17.69 & $2(6.25)$ & $\begin{array}{l}119 \\
50\end{array}$ & & \\
\hline Gestante & 53 & 7.75 & $3(18.75)$ & 50 & & \\
\hline Vacía & 115 & 16.81 & $1(6.25)$ & & & \\
\hline Recién Parida & 11 & 1.61 & $2(12.50)$ & 9 & & \\
\hline \multicolumn{7}{|l|}{ Uso de los caballos: } \\
\hline Competencia & 329 & 48.10 & $6(37.50)$ & 323 & \multirow[t]{2}{*}{0.10} & \multirow[t]{2}{*}{$0.25(0.04-1.35)$} \\
\hline No competencia & 355 & 51.90 & $10(62.50)$ & 345 & & \\
\hline \multicolumn{7}{|l|}{ Alimentación: } \\
\hline Forraje & 325 & 47.51 & $9(56.25)$ & 316 & \multirow{3}{*}{0.06} & \multirow{3}{*}{$1.14(0.27-4.76)$} \\
\hline Pastoreo & 269 & 39.33 & $4(25.00)$ & 265 & & \\
\hline Mixto & 90 & 13.16 & $3(18.75)$ & 87 & & \\
\hline \multicolumn{7}{|l|}{ Alojamiento: } \\
\hline Caballeriza & 340 & 49.71 & $8(50.00)$ & 332 & 0.20 & $3.12(0.49-21)$ \\
\hline Potrero & 344 & 50.29 & $8(50.00)$ & 336 & & \\
\hline Conviven otros & & & & & 0.04 & $2.34(0.28-19)$ \\
\hline
\end{tabular}




\begin{tabular}{|c|c|c|c|c|c|c|}
\hline animales: & 598 & 87.43 & $15(93.75)$ & 583 & & \\
\hline $\mathrm{Si}$ & 86 & 12.57 & $1(6.25)$ & 85 & & \\
\hline \multicolumn{7}{|l|}{ No } \\
\hline \multicolumn{7}{|c|}{ Fuentes de agua: } \\
\hline Pozo abierto & 341 & 49.85 & $8(50.00)$ & 333 & 0.78 & $0.86(0.31-2.41)$ \\
\hline Bordo & 343 & 50.15 & $8(50.00)$ & 335 & & \\
\hline Total & 684 & 100.00 & $16(100.00)$ & 668 & - & - \\
\hline
\end{tabular}

\section{Discusión}

La neosporosis en caballos ha sido reportada a nivel mundial con diferente seroprevalencia ${ }^{(23-26)}$. En el presente estudio se detectó el $2.34 \%$ de anticuerpos anti-Neospora spp. en caballos de cuatro regiones de México. Otros estudios han reportado seroprevalencias similares al presente, en Brasil del $2.5 \%$ y $4.1 \%$ a la presencia de Neospora spp. ${ }^{(6,18)}$, Costa Rica el $3.5 \%$, Nineveh región de Iraq $3.7 \%$ y en Durango, México reportaron una seroprevalencia del $3 \%$ a la presencia de anticuerpos anti- $N$. hughesi ${ }^{(27-29)}$, sin embargo se han reportado seroprevalencias más altas a la presencia de anticuerpos anti- Neospora caninum en Estados Unidos $34 \%$, Irán $20 \%$, Brasil $48.27 \%$ y Perú $12 \%{ }^{(23-26)}$. La importancia de detectar en caballos la presencia de anticuerpos anti- Neospora spp., contribuye con la aportación del estado epidemiológico que guarda esta enfermedad en México, y en esta especie que representa un sistema productivo importante en las explotaciones pecuarias. La seroprevalencia a Neospora spp. detectada en hembras y machos fue de $2.7 \%$ y $2.0 \%$ respectivamente. Estudios en Brasil reportaron un $4.3 \%$ en hembras y $3.7 \%$ en machos $^{(6)}$; a diferencia de los resultados de Israel que fueron el 13,0 \% en machos y $10.9 \%$ en hembras $^{(8)}$, coincide con lo reportado en Brasil, que a pesar de no ser estadísticamente significativo, se debe observar que tienen similitud de riesgo de infección tanto hembras como machos.

Los caballos que participaron en el presente estudio, fueron de diferentes regiones de México, observándose que las regiones occidente y sur presentaron un mayor porcentaje de caballos positivos a la presencia de anticuerpos anti-Neospora spp. en comparación de la región centro y norte. Estudios similares reportaron que en Brasil hubo variaciones $5.6 \%$ y $2.6 \%$ en las regiones costeras y de las montañas respectivamente ${ }^{(6)}$; en Jordania también se documenta la presencia del parásito en los caballos de acuerdo a su ubicación ${ }^{(30)}$, esto podría sugerir la influencia de la presencia de Neospora spp. en caballos por su localización geográfica y el clima de cada región.

En este estudio se obtuvo un OR de 1.1 para las variables edad, raza y alimentación, no observándose diferencia estadística. Estos resultados coinciden con los reportes de Israel $^{(8)}$, Brasil $^{(25)}$, Jordania ${ }^{(30)}$ e Italia ${ }^{(31)}$, y se puede considerar que estas variables, aunque no sean 
estadísticamente significativas, la importancia biológica como factor de riesgo es mayor con su incremento, aumenta la probabilidad de adquirir la infección de este parásito. Para la variable tipo de alojamiento el OR obtenido fue de 3.12 en este estudio, coincidiendo con lo reportado en Israel $^{(8)}$, considerándose como un factor de riesgo para aumentar la probabilidad de infección a Neospora spp. La variable convivencia con otros animales asociada a la presencia de Neospora spp., el OR obtenido fue $2.34(P<0.05)$, coincidiendo con diversos estudios realizados principalmente en Brasil ${ }^{(5,6,25)}$, que analizaron la misma variable con un OR $1.35(P<0.05)$. Estos resultados indican, que la presencia de otros animales aumenta el riesgo de los caballos a adquirir el parásito Neospora spp.

\section{Conclusiones e implicaciones}

En este estudio se identificaron anticuerpos anti Neospora spp. en los caballos de las regiones estudiadas, lo que implica el riego de la presencia de Neosporosis en las explotaciones equinas; de los casos positivos ninguno mostro signos clínicos característicos de la enfermedad. La variable convivencia con otros animales es el factor de riesgo que presentó mayor relación con la seropositividad, sin embargo, es necesario realizar un análisis considerando las diferentes categorías de cada variable. Se requiere realizar estudios que permitan identificar al huésped definitivo para conocer mejor el mecanismo de transmisión de la enfermedad a los caballos, e identificar de manera precisa la especie de Neospora presente en caballos.

\section{Agradecimientos}

Se agradece a los propietarios de los animales incluidos en el estudio por las facilidades prestadas para el desarrollo del trabajo.

\section{Literatura citada:}

1. Dubey JP, Porterfield, ML. Neospora caninum (Apicomplexa) in an aborted equine fetus. Int J Parasitol 1990;76:732-734.

2. Lindsay DS, Steinberg H, Dubielzig RR, Semrad SD, Konkle DM, Miller PE, et al. Central nervous system neosporosis in a foal. J Vet Diagn Invest 1996;8:507-510.

3. Marsh AE, Barr BC, Packham AE, Conrad PA. Description of a new Neospora species (Protozoa: Apicomplexa: Sarcocystidae). J Parasitol 1998;84(5):983-991.

4. Goodswen SJ, Kennedy PJ, Ellis JT. A review of the infection, genetics, and evolution of Neospora caninum: from the past to the present. Infect Genet Evol 2013;13:133-150. 
5. Abreu RA, Weiss RR, Thomaz-Soccol V, Locatelli-Dittrich R, Laskoski LM, Bertol MA, et al. Association of antibodies againts Neospora caninum in mares with reproductive problems and presence of seropositive dogs as a risk factor. Vet Parasitol 2014;202(34):128-131.

6. Moura AB, Silva MO, Farias JA, Vieira-Neto A, Souza AP, Sartor AA. Neospora spp. antibodies in horses from two geographical regions of the states of Santa Catarina, Brazil. Rev Bras Parasitol Vet 2013;22(4): 597-601.

7. Veronesi F, Diaferia M, Mandara MT, Marenzoni ML, Cittadini F, Piergili-Fioretti DP. Neospora spp. infection associated with equine abortion and/or stillbirth rate. Vet Res Commun 2008;32: 223-226.

8. Kligler EB, Shkap V, Baneth G, Mildenberg Z, Steinman A. Seroprevalence of Neospora spp. among asymptomatic horses, aborted mares and horses demonstrating neurological signs in Israel. Vet Parasitol 2007;148:109-113.

9. Renier AC, Morrow JK, Graves AJ, Finno CJ, Howe DK, Owens SD, et al. Diagnosis of equine protozoal myeloencephalitis using indirect fluorescent antibody testing and enzymelinked immunosorbent assay titer ratios for Sarcocystis neurona and Neospora hughesi. J Equine Vet Sci 2016;36:49-51.

10. Antonello AM, Pivoto FL, Camillo G, Braunig P, Sangioni LA, Pompermayer E, et al. The importance of vertical transmission of Neospora sp. in naturally infected horses. Vet Parasitol 2012;187:367-370.

11. Finno CJ, Eaton JS, Alemán M. Hollingsworth SR. Equine protozoal myeloencephalitis due to Neospora hughesi and equine motor neuron disease in a mule. Vet Ophthalmol 2010;13(4):259-265.

12. Dubey JP, Calero-Bernal R, Rosenthal BM, Speer CA, Fayer R. Sarcocystosis of animals and humans. 2nd ed. Boca Raton, Florida: CRC Press.; 2016.

13. McAllister MM, Dubey JP, Lindsay DS, Jolley WR, Wills RA, McGuire AM. Rapid communication: Dogs are definitive hosts of Neospora caninum. Int $\mathrm{J}$ Parasitol 1998;28(9):1473-1499.

14. Gondim LFP, McAllister MM, Pitt WC, Zemlicka DE. Coyotes (Canis latrans) are definitive hosts of Neospora caninum. Int J Parasitol 2004;34:159-166.

15. King JS, Slapeta J, Jenkins DJ, Al-Qassab SE, Ellis JT, Windsor PA. Australian dingoes are definitive hosts of Neospora caninum. Int J Parasitol 2010;40:945-950. 
16. Dubey JP, Jenkins MC, Rajendran C, Miska K, Ferreira LR, Martins J, et al. Gray wolf (Canis lupus) is a natural definitive host for Neospora caninum. Vet Parasitol 2011;181:382387.

17. Dubey JP, Schares G. Neosporosis in animals-the last five years. Vet Parasitol 2011;180:90108.

18. Hoane JS, Gennari SM, Dubey JP, Ribeiro MG, Borges AS, Yai LE, et al. Prevalence of Sarcocystis neurona and Neospora spp. infection in horses from Brazil based on presence of serum antibodies to parasite surface antigen. Vet Parasitol 2006;136:155-159.

19. Dubey JP, Hemphill A, Calero-Bernal R, Schares G. Neosporosis en animales. Boca Raton, Florida: CRC Press.; 2017.

20. Pusterla N, Conrad PA, Packham AE, Mapes SM, Finno CJ, Gardner IA, et al. Endogenous transplacental transmmission of Neospora hughesi in naturally infected horses. J Parasitol 2011;97:281-285.

21. Gondim LF, Lindsay DS, McAllister MM. Canine and bovine Neospora caninum control sera examined for cross-reactivity using Neospora caninum and Neospora hughesi indirect fluorescent antibody tests. J Parasitology 2009;95(1):86-88.

22. Al-Qassab S, Reichel MP, Ivens A, Ellis JT. Genetic diversity amongst isolates of Neospora caninum, and the development of a multiplex assay for the detection of distinct strains. Mol Cell Probes 2009;23:132-139.

23. James KE, Smith WA, Conrad PA, Packham AE, Guerrero L, Ng M, et al. Seroprevalence of Sarcocystis neurona and Neospora hughesi among healthy horses in the United States. Proc Am Assoc Equine Pract. 2015;61:524.

24. Tavalla M, Sabaghan M, Abdizadeh R, Khademvatan S, Rafiei A, Razavi-Piranshahi A. Seroprevalence of Toxoplasma gondii and Neospora spp. infections in Arab horses, southwest of Iran. J J Microbiol 2015;8:e14939.

25. Cazarotto CJ, Balzan A, Grosskopf RK, Boito JP, Portella LP, Vogel FF, et al. Horses seropositive for Toxoplasma gondii, Sarcocystis spp. and Neospora spp.: Possible risk factors for infection in Brazil. Microb Pathog 2016;99:30-35.

26. Luza M, Serrano-Martínez E, Tantaleán M, Quispe M, Casas G. Primer reporte de Neospora caninum, en caballos de carrera de Lima, Perú. Salud Tecnol Vet 2013;1:40-45. 
27. Dangoudoubiyam S, Oliveira JB, Víquez C, Gómez-García A, González O, Romero JJ. Detection of antibodies against Sarcocystis neurona, Neospora spp., and Toxoplasma gondii in horses from Costa Rica. J Parasitol 2011;97:522-524.

28. Al-Obaidii WA, Al-Kennany ER. Investigation of Neospora hughesi antibodies by using ELISA in horses in Nineveh Province. Assiut Veterinary Med J 2014;60:167-170.

29. Yeargan MR, Alvarado-Esquivel C, Dubey JP, Howe K. Prevalence of antibodies to Sarcocystis neurona and Neospora hughesi in horses from Mexico. Parasite 2013;20:29.

30. Talafha AQ, Abutarbush SM, Rutley DL. Seroprevalence and potential risk factors associated with Neospora spp. infection among asymptomatic horses in Jordan. Korean $\mathrm{J}$ Parasitol 2015;53:163-167.

31. Bártová E, Machacová T, Sedlák K, Budíková M, Mariani U, Veneziano V. Seroprevalence of antibodies of Neospora spp. and Toxoplasma gondii in horses from southern Italy. Folia Parasitol (Praha) 2015;62:043. 